\title{
ASSESSMENT OF PROFESSIONAL'S ADHERENCE TO JOINT NATIONAL COMMITTEE 8 GUIDELINES IN THE MANAGEMENT OF HYPERTENSION
}

\author{
SCHNELL JENNIFER D’SOUZA ${ }^{1}$, ANCEL NEETHU MANI ${ }^{1}$, NIMISHA KURIAN ${ }^{1}$, JAIKANTH ${ }^{2 *}$ \\ ${ }^{1}$ Department of Pharmacy Practice, Karavali College of Pharmacy, Mangalore, Karnataka, India. ${ }^{2}$ Department of Pharmacology, Karavali \\ College of Pharmacy, Mangalore, Karnataka, India. Email: jaikanthjai@gmail.com
}

Received: 14 July 2018, Revised and Accepted: 31 August 2018

\section{ABSTRACT}

Objectives: Hypertension is the most insidious ailment in primary care with its management being a daily affair. The avail of antihypertensive medications has affirmed their efficacy in blood pressure alleviation. Yet, the methodical choice of medication with which treatment ought to commence at the precise blood pressure threshold and maintained at a target level was undiscerned. Consequently, the Eighth Joint National Committee grants an evidence-based tool, which was employed in the appraisal of professional's adherence to joint national committee 8 guidelines.

Methods: A prospective, observational study was governed. Aggregate patients with hypertension with/without diabetes mellitus (DM) and/ or chronic kidney failure admitted in general medicine and the dialysis unit of the tertiary health care hospital, for 4 months were enrolled. The rationality of antihypertensive medications and target blood pressure was noted.

Results: Patients matriculated to 125,90 males and 35 females. Average age perceived was between 51 and 60 years, with the length of stay 14.39 (standard deviation $[\mathrm{SD}] \pm 1.52$ ) and $9.3(\mathrm{SD} \pm 0.46)$ days in the respective unit. The gross medication endorsed represents 1085 medications, incorporating 337 antihypertensive medications. The optimal choice of an antihypertensive medicine was clonidine and amlodipine. Adherence in the populace with lone hypertension was cent percent, trailed by hypertension with DM $82.35 \%$ and minimal in hypertension with chronic kidney disease.

Conclusion: 86-medication compiled adherence to the guidelines (25.52\%). Rationality of medication depicts $25.6 \%$ were rational and $73.6 \%$ distinguish as non-rational, amid a demise of a sole victim. A significant high-grade defiance of health-care practitioners to the Eighth Joint National Committee guidelines was evidenced from our study.

Keywords: Joint national committee 8, Adherence, Hypertension, Medication regimen.

(C) 2019 The Authors. Published by Innovare Academic Sciences Pvt Ltd. This is an open access article under the CC BY license (http://creativecommons. org/licenses/by/4. 0/) DOI: http://dx.doi.org/10.22159/ajpcr.2019.v12i1.28451

\section{INTRODUCTION}

Hypertension asserted by the World Health Organization as high or elevated blood pressure. An infirmity in which the blood vessels has persistently escalate pressure, fostering the heart to pump harder [1]. It is the most insidious ailment in primary care with its management being a daily affair [2]. Clinching an asymptomatic complexion has secured it as an alias of "the silent killer" [3]. The expectancy of encountering hypertension is gauged at $90 \%$ [4], with it affecting nearly $26 \%$ of adult population currently and projected to affect 1.56 billion (29\%) of the world's adult population by 2025 . Its pervasiveness in India is 66 million with 34 million in urban and 32 million in rural areas [5]. India is cruising through a demographic metamorphosis as a developing country with an amplification in population trends. This momentous proliferation of life can genesis non-communicable disease toward eclipsing infectious disease that implicates a stain on the health finances of the country [6].

Hypertension and diabetes mellitus (DM) are overt to coexist in various populations [7]. In accordance with the WHO, DM incidence in adults worldwide was accounted for $4.0 \%$ in 1995 . It is predicted to levitate to $5.4 \%$ by the year 2025 . The adulated populace would mount from 135 million in 1995 to 300 million in the year 2025. The peril of cardiovascular disease amplified by an aspect of two to three in DM populace with every level of systolic pressure [8]. In inhabitants of DM in tandem with hypertension, an attenuation in blood pressure poses an early benefit in results and enhanced cost-effectiveness, then maintaining a taut control over blood glucose levels [9]. DM is cardinal in conjunction with hypertension designated the secondary source, yet an autonomous menace in end-stage renal disease (ESRD). The sequentially chronic renal disease can instigate or be a consequence of hypertension [10]. Predominantly, renal disease populace is inflicted with hypertension as well, thus navigating to the deterioration of kidney function. Hence, the preventive stratagem in ESRD ought to comprise the prevention, treatment, and control of blood pressure [11].

Up until 1950, there was no effectual treatment available in the management of hypertension. With the development of antihypertensive and their efficacy in plummeting blood pressure in the past 3 decades has tinted it as a therapeutic coup [12]. Conversely, the proficient choice of an antihypertensive medication with which treatment ought to be instigated, at precise blood pressure threshold and sustain at target level was unresolved [13]. Therefore, the Eighth Joint National Committee on the prevention, detection, evaluation, and treatment of elevated blood pressure endows an evidence-based tool for a physician in the clinical advance of hypertension management [14]. The Joint National Committee is punctilious as the "golden standard" hypertension management [15]. The 2014 Joint National Committee-8 (JNC-8) guidelines encompass rigorous scientific evidence and nine recommendations comprised by reviewing studies of hypertensive natives aged eighteen and elder [16]. They urge the use of four types of medication - calcium channel blockers (CCBs), angiotensin-converting enzyme inhibitors (ACEIs), angiotensin receptor blockers (ARBs), and diuretics on mainstay of randomized control trial evidence, with explicit recommendations according to race, chronic kidney disease (CKD), or diabetic status [17].

The current study aims to analyze the comorbidities in the populace deliberated, assess the physicians prescribing pattern of 
antihypertensive medications, its rationality, and adherence to JNC-8 guidelines. Rational prescription pattern utilizes the least number of medicaments to obtain the best possible therapeutic outcome in the shortest time duration. The management of hypertension requires both pharmacological and non-pharmacological methods [18]. Therefore, compliance with such guideline grants stanchion, due to an optimal management of an independent citizen's treatment regimen.

\section{MATERIALS AND METHODS}

A prospective observational study was undertaken in the general Medicine and Dialysis Department of Father Muller Medical College Hospital, Mangalore, India. For a duration of 4 months, from November 2016 to February 2017, after the authorization of the institutional ethics committee (FMMC/FMIEC/3054/2016). A sum of 125 individuals was integrated into the study. All hypertension populaces of age 1860 years admitted to the inpatient general medicine and dialysis in and outpatient ward, including folks with comorbidities of DM and/or CKD were incorporated. While patients with incomplete data or those reassigned to other departments in the span of 24 hours were excluded. The inhabitant's information was compiled and documented in the data collection form generated. Medication adherence and rationality were assessed by weighing it against the treatment algorithm calibrated by the Eighth Joint National Committee of hypertension management. Medication units consumed were appraised by computing its daily define dose.

\section{Statistical analysis}

Statistical software SPSS (version 20) was employed for data analysis. Descriptive statistics such as percentages were reckoned for categorical variables. The mean and the standard deviation were employed to estimate continuous variables. Graphic representations were performed using Microsoft Excel 2007 for visual interpretation of analyzing data.

\section{RESULTS}

A total of 125 prescriptions were analyzed, 69 received from general medicine and 56 from dialysis ward. The study constituted of 90 (72\%) males and 35 (28\%) females populace. The age allocation was foremost seen amid 51-60 years (44\%) and minimal in 18-28 years (5.6\%), retaining a mean of 31.3 (standard deviation [SD] \pm 23.8 ). The average length of stay was $14.39(\mathrm{SD} \pm 1.52)$ and $9.3(\mathrm{SD} \pm 0.46)$ days in the respective wards.

On appraising the aggregate of medication prescribed, 1085 medicines were achieved. The recurrent integer of medication consumed per individual was estimated at 6-10 (37.7\%) with a bare minimum of 1-5 (29\%) medications, preserving a mean of 14.9 (SD \pm 1.5$)$. Correspondingly, the antihypertensive medications cumulated to 337 , with peak quantity consumed 3-4 (45.6\%), shadowed by 1-2 (44.8\%), and $\geq 5$ (9.6\%), with mean 41.7 (SD \pm 25.7$)$ (Table 1).

The survey of 125 populaces acquired 7 (5.6\%) lone hypertension individuals, in conjugation with $17(13.6 \%)$ inhabitants possessing DM, 65 (52\%) people with chronic kidney failure, and 36 (28.8\%) patients have both of them as comorbidity (Fig. 1).

The overview of this study furnishes amlodipine as the most substantial prescribed antihypertensive medication with 1.95 units utilized. The predominant therapy spotted was triple combination therapy 35 (28\%), succeeded by monotherapy 31 (24.8\%), double combination therapy $31(24.8 \%)$, and trailed by multiple combination therapy $28(22.4 \%)$ (Table 2).

When contemplating the class of medication prescribed in hypertension and its comorbidities, the predominant choice of medication was CCBs, pursued by ARBs in hypertension lone patients, similarly, $\beta$ blockers in populaces with DM, $\alpha 2$ agonist in individuals with CKD as comorbidity, and ARBs in inhabitants with both as comorbidity as shown in Fig. 2. The corresponding unit of
Table 1: Demographic data and patient details

\begin{tabular}{ll}
\hline Characteristics & Number of patients (\%) \\
\hline Gender & \\
Male & $90(72)$ \\
Female & $35(28)$ \\
Age distribution & $7(5.6)$ \\
18-28 & $15(12)$ \\
$29-39$ & $48(38.4)$ \\
$40-50$ & $55(44)$ \\
$51-60$ & $31.3 \pm 23.8$ \\
Mean \pm SD & \\
Total medications prescribed & $24(19.2)$ \\
$1-5$ & $75(60)$ \\
$6-10$ & $26(20.8)$ \\
$\geq 11$ & $41.7 \pm 28.9$ \\
Mean \pm SD & \\
Antihypertensive medications & \\
prescribed & $56(44.8)$ \\
$1-2$ & $57(45.6)$ \\
$3-4$ & $12(9.6)$ \\
$\geq 5$ & $41.7 \pm 25.7$ \\
Mean \pm SD & \\
Length of stay in general medicine & \\
department & \\
1-5 & $20(29)$ \\
6-10 & $26(37.7)$ \\
$11-15$ & $11(15.9)$ \\
$\geq 21$ & $6(8.7)$ \\
Death & $1(1.4)$ \\
Mean \pm SD & $14.9 \pm 1.5$ \\
Length of stay in dialysis department & \\
Twice in a week & $39(69.6)$ \\
Thrice in a week & $17(30.4)$ \\
Mean \pm SD & $9.3 \pm 0.5$ \\
\hline SD:Stand &
\end{tabular}

SD: Standard deviation

Table 2: Prescribing pattern of antihypertensive medications

\begin{tabular}{ll}
\hline Treatment & Number of prescriptions (\%) \\
\hline Monotherapy & $31(24.8)$ \\
CCBs & $18(58.06)$ \\
Double combination therapy & $31(24.8)$ \\
CCBs $+\alpha_{2}$ agonist & $7(22.58)$ \\
Triple combination therapy & $35(28)$ \\
CCB $+\alpha_{2}$ agonist+diuretics $/ \beta$ blocker & $5(14.28)$ \\
Multiple therapy & $28(22.4)$ \\
CCBs+CCBs $+\beta$ blockers $+\alpha_{2}$ agonist & $6(21.43)$ \\
\hline
\end{tabular}

CCBs: Calcium channel blockers

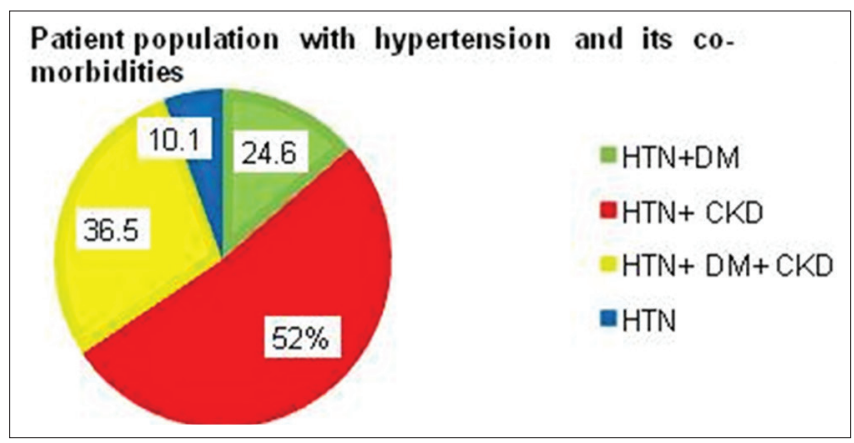

Fig. 1: Disease distribution

antihypertensive medication consumed by total populace is depicted in Table 3.

The adherence attained in the populace with hypertension lone was cent percent. Minimal adherence was ascertained in hypertension with 
Table 3: Antihypertensive medication utilization

\begin{tabular}{llllllll}
\hline Medication class & $\begin{array}{l}\text { Generic } \\
\text { name }\end{array}$ & $\begin{array}{l}\text { ATC } \\
\text { code }\end{array}$ & $\begin{array}{l}\text { Route of } \\
\text { admission }\end{array}$ & $\begin{array}{l}\text { Daily defined } \\
\text { dose }(g)\end{array}$ & $\begin{array}{l}\text { Number of } \\
\text { prescription }\end{array}$ & $\begin{array}{l}\text { Total units } \\
\text { consumed (g) }\end{array}$ & $\begin{array}{l}\text { Daily defined } \\
\text { dose/100-bed days }\end{array}$ \\
\hline Angiotensin-converting & Enalapril & $\mathrm{C}_{09} \mathrm{AA}_{02}$ & Oral & 0.01 & 6 & 2.75 & 0.022 \\
enzyme inhibitors & Ramipril & $\mathrm{C}_{090} \mathrm{AA}_{05}$ & Oral & 0.0025 & 5 & 5 & 0.221 \\
$\beta$-blockers & Atenolol & $\mathrm{C}_{07} \mathrm{AB}_{03}$ & Oral & 0.075 & 5 & 3.8 & 0.0032 \\
& Bisoprolol & $\mathrm{C}_{07} \mathrm{AB}_{07}$ & Oral & 0.01 & 1 & 1 & 0.0082 \\
& Metoprolol & $\mathrm{C}_{07} \mathrm{AB}_{02}$ & Oral & 0.15 & 7 & 25.32 & 0.0488 \\
& Propranolol & $\mathrm{C}_{07} \mathrm{AA}_{05}$ & Oral & 0.16 & 1 & 0.125 & 0.00006 \\
$\alpha$ agonist & Timolol & $\mathrm{C}_{07} \mathrm{AA}_{06}$ & Oral & 0.02 & 5 & 25 & 0.102 \\
CCBs & Clonidine & $\mathrm{C}_{02} \mathrm{AC}_{01}$ & Oral & 0.00045 & 50 & 48555.3 & 1190.1 \\
& Amlodipine & $\mathrm{C}_{08} \mathrm{CA}_{01}$ & Oral & 0.005 & 55 & 57 & 1.954 \\
ARBs & Cilnidipine & $\mathrm{C}_{08} \mathrm{CA}_{14}$ & Oral & 0.01 & 49 & 68 & 0.9451 \\
Thiazide-type diuretics & Nifedipine & $\mathrm{C}_{08} \mathrm{CA}_{05}$ & Oral & 0.03 & 26 & 13.26 & 0.065 \\
& Telmisartan & $\mathrm{C}_{09} \mathrm{CA}_{07}$ & Oral & 0.04 & 10 & 16 & 0.01949 \\
& Furosemide & $\mathrm{C}_{03} \mathrm{CA}_{01}$ & Oral & 0.04 & 5 & 8 & 0.01169 \\
$\alpha$-blocker & Torsemide & $\mathrm{C}_{03} \mathrm{CA}_{04}$ & Oral & 0.015 & 9 & 12 & 0.024 \\
$\alpha+\beta$ blocker & Metolazone & $\mathrm{C}_{03} \mathrm{BA}_{08}$ & Oral & 0.005 & 1 & 39.36 & 1.0804 \\
& Prazosin & $\mathrm{CO}_{2} \mathrm{CA}_{01}$ & Oral & 0.005 & 6 & 1 & 0.016 \\
Vasodilator & Labetalol & $\mathrm{C}_{07} \mathrm{AG}_{01}$ & Oral & 0.6 & 7 & 6 & 0.654 \\
& Carvedilol & $\mathrm{C}_{07} \mathrm{AG}_{02}$ & Oral & 0.0375 & 21 & 7.96 & 0.00073 \\
\hline
\end{tabular}

ATC: Anatomical therapeutic chemical, ARBs: Angiotensin receptor blockers, CCBs: Calcium channel blockers

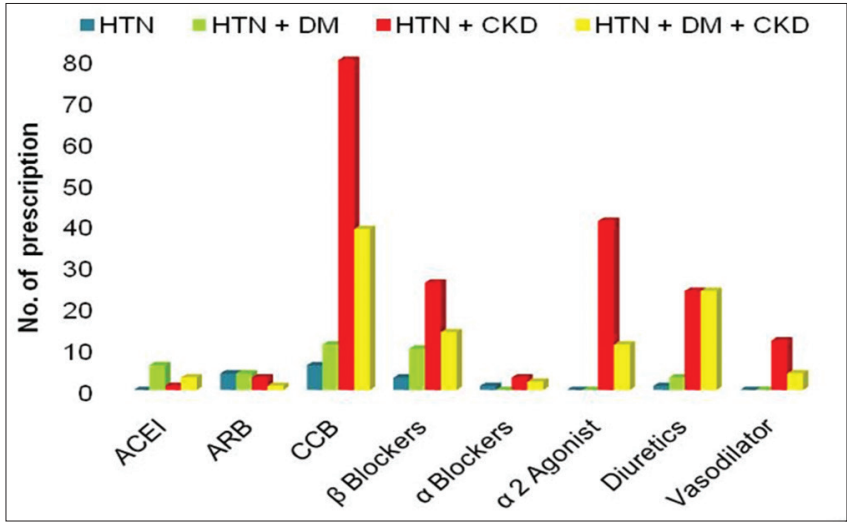

Fig. 2: Antihypertensive medication class prescribed for hypertension with its comorbidities

DM and CKD 19 (7.7\%). Adherence of antihypertensive medication was $86(25.52 \%)$. The investigation of populace blood pressure on admission to the hospital confers 11 inhabitants with normal blood pressure, in collaboration with 20 prehypertension, 36 Stage I hypertension, and 58 Stage II hypertension. The demise of a sole victim was witnessed. The rationality of antihypertensive medications portrayed, 32 (25.6\%) rational while 92 (73.6\%) were non-rational (Table 4).

\section{DISCUSSION}

Hypertension represents a predominant medical condition worldwide, a principal cause of stroke and a primary menace for coronary artery disease and its complications. The vital goal of treating it is to preclude and dwindle the prospect of hypertension-associated morbidity and mortality. The Eighth Report of the Joint National Committee on the prevention, detection, evaluation, and treatment of high blood pressure bequeaths a prominent evidence-based clinical guideline for the management of hypertension. The overview of this study depicts the incidence of hypertension was $90(72 \%)$ males and $35(28 \%)$ female, which is parallel to the findings of Kothari $\mathrm{N}$ and Ganguly B, where primacy was top in male $474(52.7 \%)$ than in female $425(47.3 \%)$ [14]. The age allocation in our survey was chiefly amid $51-60$ years $(44 \%)$ and least in $18-28(5.6 \%)$, this is contradictory to the analysis bared by Tadvi AY and Bandi JR, in which there were 73 hypertensive participants, 12 (16.4\%) in 20-25 years, 16 (21.9\%) in 26-
30 years, 24 (32.9\%) participants between 31 and 35, and 21 (28.8\%) in the age group of 36-40 years [19]. The present study confers the sum of antihypertensive medications prescribed to be 337 . The repeated count consumed by inhabitants was 3-4 (45.6\%), trailed by 1-2 (44.8\%), and $\geq 5(9.6 \%)$ medications. This is on par with that uncovered by Shah et al., in which a total of 63 antihypertensive medication were prescribed for 50 patients, where $38(76 \%)$ received one medication followed by $11(22 \%)$ who received two and 1 patient $(2 \%)$ who received three medications of different antihypertensive class, respectively [20]. Of the 125 populaces appraised, 7 (24.6\%) were lone hypertensive, 17 (13\%) had DM, and $65(10.1 \%)$ had chronic kidney failure as comorbidity, whereas $36(28.8 \%)$ had both of them as comorbidities. This challenge, the investigation was done by Mohan, was among the 325 patients, $71.42 \%$ had DM with hypertension, and $28.57 \%$ had respiratory disorders with hypertension [21]. The predominant therapy was triple combination $35(28 \%)$, succeeded by monotherapy $31(24.8 \%)$, double $31(24.8 \%)$, and trailed by multiple combination therapy $28(22.4 \%)$ which was paradoxical to the examination undertaken by Kothari N and Ganguly B that showed $45.60 \%$ of patients were stabilized on monotherapy, whereas $54.4 \%$ of patients were on multiple medication therapy [14]. The outcomes of this study exhibit, CCBs represent the prime choice of antihypertensive class, pursued by ARBs in hypertensive lone patients, similarly, $\beta$-blockers in populaces with DM, $\alpha 2$ agonist in individuals with CKD as comorbidity, and ARBs in inhabitants with both as comorbidities. When comprehending the substantial antihypertensive medication prescribed, amlodipine attained that spot with 1.95 units being consumed, an analysis conducted by Sweileh et al. gainsaid these findings by stating that ACE-I was the most common medication class both in mono and combination therapy [22]. The conclusion met in our study portrays, adherence attained in the populace with hypertension lone was cent percent. Minimal was ascertained in hypertension with DM and CKD 19 (7.7\%). The adherence of populaces in disease state corresponds an adherence of $86(25.52 \%)$ antihypertensive medications. This defies the finds of Kothari N and Ganguly B [14], in which $60 \%$ of antihypertensive prescribed in this group did not follow JNC-8 and the WHO guidelines. The recent study provides a limited external validity, as the sample obtained was not a representation of an entire population; it represents only the populace that was acquainted with the hospital where the investigation was executed. A certain amount of recall bias may be absorbed, as information concerning patient treatment was attained from medical records, thus posing a minimal limitation. 


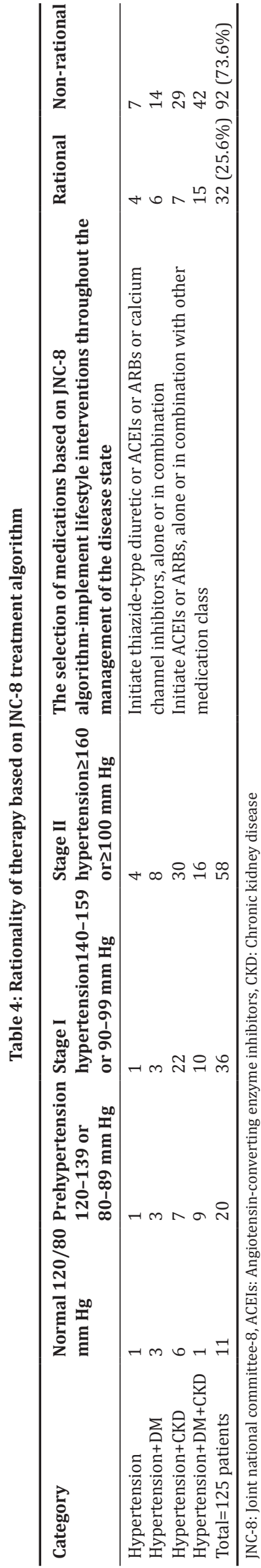

\section{CONCLUSION}

This prospective, observational study was embarked to investigate the prescribing patterns of antihypertensive medication, its adherence, and rationality with JNC 8 guidelines of hypertension management. The core findings propose that triple combination therapy was essentially prescribed, hypertension with CKD was the chiefly surveyed disease state. The predominant predilection for medication was CCBs. Rationality and adherence were revered at $25.6 \%$ and $25.5 \%$. In this contemporary scenario, vaster populations of hypertensive individuals are afflicted with comorbidities. Contrarily, it is a sovereign peril for major disease conditions. Hence, the key to optimizing patients' quality of life is preliminary blood pressure management. The lack of implementation of treatment algorithm has yielded a suboptimal adherence and rationality in the medication prescribed. Thus, education of professional's about adherence to currently available and beneficial guidelines in patient's therapy is crucial. Maintaining individual target blood pressure with a habitual checkup retaining a clinical pharmacist to provide knowledge about the imperatives of adherence to lifestyle modification and medication prescribed can be beneficial in treatment management.

\section{ACKNOWLEDGMENTS}

Our earnest gratitude to the entire faculties of General Medicine and Dialysis Department of Father Muller Medical College Hospital, Mangalore, India. Above all are humble admiration for the whole populace for their cooperation.

\section{AUTHORS' CONTRIBUTION}

All four authors have constituted a substantial contribution to the study concept, data collection, its analysis, and interpretation. All authors have partaken in drafting the manuscript and in its final submission.

\section{CONFLICTS OF INTEREST}

The authors declare that they have no conflicts of interest.

\section{REFERENCES}

1. World Health Organization. Q and A on Hypertension. Available from: http://www.who.int.features.

2. O'Callaghan CJ, Goh MY, Rong P. Hypertension - The difficult decisions. Aust Fam Physician 2013;42:376-9.

3. Jackson JH, Sobolski J, Krienke R, Wong KS, Frech-Tamas F, Nightengale B, et al. Blood pressure control and pharmacotherapy patterns in the United States before and after the release of the joint national committee on the prevention, detection, evaluation, and treatment of high blood pressure (JNC 7) guidelines. J Am Board Fam Med 2008;21:512-21.

4. Raju S, Solomon S, Karthik N, Clara AJ, Venkatanarayanan A. Assessment of prescribing pattern for hypertension and comparison with JNC-8 guidelines-proposed intervention by clinical pharmacist. J Young Pharm 2016;8:133-5.

5. Sunitha P, Kaveri DL, Soumya P, Arundhati D. Effect of pharmacist mediated patient counseling in hypertensive patients in terms of knowledge, compliance and lifestyle modification. Int J Pharm Pharm Sci 2014;4:277-81.

6. Galav A, Bhatnagar R, Meghwal SC, Jain M. Prevalence of hypertension among rural and urban population in Southern Rajasthan. Nat J Community Med 2015;6:174-8.

7. Mohan V, Seedat YK, Pradeepa R. The rising burden of diabetes and hypertension in Southeast Asian and African regions: Need for effective strategies for prevention and control in primary health care settings. Int J Hypertens 2013;2013:409083.

8. Ku E, Glidden DV, Johansen KL, Sarnak M, Tighiouart H, Grimes B, et al. Association between strict blood pressure control during chronic kidney disease and lower mortality after onset of end-stage renal disease. Kidney Int 2015;87:1055-60.

9. Dhanaraj E, Raval A, Yadav R, Bhansali A, Tiwari P. Prescription pattern of antihypertensive agents in T2DM patients visiting tertiary care centre in north India. Int J Hypertens 2012;2012:520915.

10. Patel RD, Shah NN. Control of blood pressure and anti-hypertensive 
medication profile in end stage renal disease patients undergoing maintenances hemodialysis: An observation and a retrospective study. Ind J Pharm Pract 2014;7:19-26.

11. Reynolds K, Gu D, Muntner P, Kusek JW, Chen J, Wu X, et al. A population-based, prospective study of blood pressure and risk for end-stage renal disease in China. J Am Soc Nephrol 2007;18:1928-35.

12. Surapaneni SS, Arifa SN, Venigalla S, Peter H PL, Pingili R, Challa SR. Assessment of antihypertensive medication utilization patterns and adherence to JNC-7 guidelines in South indian tertiary care teaching hospital. Ind J Pharm Pract 2015;8:177-82.

13. Touyz RM, Dominiczak AF. Hypertension guidelines is it time to reappraise blood pressure thresholds and targets? Am Heart Asso 2016;2016:1-2.

14. Kothari N, Ganguly B. Adherence to JNC-VII and WHO-ISH guidelines of antihypertensive medications prescribed to hypertensive patients with co-morbid conditions. Indian J Physiol Pharmacol 2015;59:48-56.

15. Romday R, Gupta AJ, Pawan Bhambani P. An assessment of antihypertensive medication prescription patterns and adherence to joint national committee- 8 hypertension treatment guidelines among hypertensive patients attending a tertiary care teaching hospital. Int $\mathrm{J}$ Res Med Sci 2016;4:5125-33.

16. Sabouhi F, Babaee S, Naji H, Zadeh AH. Knowledge, awareness, attitudes, and practice about hypertension in hypertensive patients referring to public health care centers in Khoor and Biabanak. Indian J Neonatal Med Res/Winter 2011;16:34-40.

17. Reisin E, Harris RC, Rahman M. Commentary on the 2014 BP guidelines from the panel appointed to the eighth joint national committee (JNC 8). J Am Soc Nephrol 2014;26:1-6.

18. Deepali PL, Ashiya M, Sunitha P, Arundhati D. An overview of rational prescribing pattern in hypertensive patients in tertiary care hospital. Int J Pharm Pharm sci 2016;2:273-6.

19. Tadvi AY, Bandi JR. Study of prevalence of hypertension in a young adult population of age group 20 to 40 years in an urban slum of Mumbai, Maharashtra, India. Int J Community Med Public Health 2016;3:3325-31.

20. Shah J, Khakhkhar T, Bhirud S, Shah RB, Date S. Study of utilization pattern of anti-hypertensive medications in hypertensive diabetic patients with or without reduced renal function at tertiary care teaching hospital. Int J Med Sci Public Health 2013;2:175-80.

21. Mohan M. Medication utilization evaluation of antihypertensives in a superspeciality hospital. Int J Pham Res Rev 2016;5:1-8.

22. Sweileh WM, Sawalha AF, Zyoud SH, Al-Jabi SW, Tameem EJ. Patterns of anti-hypertensive therapy in diabetic patients with and without reduced renal function. Saudi J Kidney Dis Transpl 2010;21:652-9. 